\title{
Inhibitory Effects of Some Flavonoids on Thioredoxin Reductase Purified from Chicken Liver
}

\section{-Author(s)}

Türkoğlu E.A' (iD https://orcid.org/0000-0001-7850-6456 Kuzu M" (D) https://orcid.org/0000-0002-1375-7673 Ayasan T"I (D) https://orcid.org/0000-0001-7397-6483 Inci Hiv (iD) https://orcid.org/0000-0002-9791-0435 Eratak SW (D) https://orcid.org/0000-0003-3788-8704

Department of Pharmaceutical Biotechnology, Faculty of Pharmacy, University of Health Sciences, Istanbul 34668, Turkey.

Deparment of Chemistry, Faculty of Science and Letters, Ağrı İbrahim Çeçen University, Ağrı 04100, Turkey.

III East Mediterranean Agricultural Research Institute, Karatas Road, Adana 01321, Turkey.

Department of Animal Science, Faculty of Agriculture, Bingöl University, Bingöl 12000, Turkey.

Department of Poultry Science, Akhisar Vocational School, Manisa Celal Bayar University, Manisa 45200, Turkey.

\section{ABSTRACT}

Thioredoxin reductases (TrxRs) are selenocysteine-containing flavoenzymes that reduce Trxin NADPH-dependent manner. In the view of the direct vital role of $\operatorname{Tr} x R$ in a wide range of biochemical and physiological processes, methods to inhibit this enzyme are clinically important. TrxR has recently emerged as a new candidate in anticancer drug investigations because of overexpression in tumorous cells. In this study, TrxR from chick liver was purified 94.6-fold with a yield of $4.86 \%$ and a specific activity of $0.19 \mathrm{EU} / \mathrm{mg} . \mathrm{K}_{\mathrm{M}}$ and $\mathrm{V}_{\max }$ values of TrxR for DTNB were calculated as $0.9 \mathrm{mM}$ and $0,03 \mathrm{EU} / \mathrm{mL}$, respectively. Then, the effects of the flavonoids hesperidin, naringenin, chlorogenic acid, ferulic acid, naringin, 3,4-dihydoxybenzoic acid, and ellagic acid on the enzyme activity were evaluated under in-vitro conditions. Ellagic acid showed the strongest inhibitory activity on TrxR with a I $C_{50}$ value of 18 $\mu \mathrm{M}$, followed by naringenin and chlorogenic acid with $\mathrm{IC}_{50}$ values of $46.7 \mu \mathrm{M}$ and $75.8 \mu \mathrm{M}$, respectively. Our results showed that flavonoids as natural products are potential inhibitors of TrxRs and the flavonoid content in animal diets may alter metabolic pathways by influencing TrxR activity.

\section{INTRODUCTION}

All organisms possess effective enzyme systems in their metabolism (Hirt et al., 2002; Arnér\& Holmgren, 2000). The thioredoxin system plays a vital role in cell functions by regulating cell redox signaling and redox environment (Montano et al., 2014), and consists of thioredoxin (Trx), NADPH, and thioredoxin reductase (Holmgren \& Lu, 2010). Thioredoxin reductases (EC 1.8.1.9) are selenium-containing flavoenzymes that reduce NADPH into Trx (Akyol \&Kuzu, 2017; Arner, 2009). Two known types of TrxR are present in the living world. The first one, a homodimer with $35 \mathrm{kDa}$ subunits, is found in prokaryotes, yeast and plants, the second, a homodimeric structure with 55-65 kDa subunits, is found in some lower eukaryotes and animals (Pacitti et al., 2014). Two major TrxR isoforms are located in different cellular microenvironments inside the cell. TrxR1 is cytoplasmic protein, also found in the nucleus, whereas TrxR2 is expressed in mitochondria. Although the two isoforms have different gene expression patterns and are located different cell compartments cell, their structures and catalytic mechanisms show same features (Duan et al., 2014).

TrxR is an essential enzyme found in all living creatures and its level in tumorous cells is 10-fold or higher than that present in normal cells (Becker et al., 2000). Due to its overexpression in tumorous cells, TrxR has attracted the attention of researchers as a possible candidate for anticancer therapies (Lu et al., 2006; Choi et al., 2002; Soini et al., 2001). TrxR has been regarded as a key therapeutic target for the design of novel anticancer drugs and inhibitors of the thioredoxin system, and 
play promising role in anticancer treatments (Zhou et al., 2013). To date, an increasing number of TrxR inhibitors have been identified, including ions (Temel et al., 2017), nitrosureas, organochalcogenides, texaphyrins (Bindoli et al., 2009), gold- and platinumcontaining compounds (Cai et al., 2012), nitroaromatic compounds (Urig \& Becker, 2006), drugs (Wang et al., 2008), biometabolites (Powis et al., 2006), which are potential TrxR inhibitors with a nanomolar to micromolar $\mathrm{IC}_{50}$ range.

Natural product derivatives are valuable candidates for the treasure of pharma and have played a crucial role in the discovery of novel therapeutics since the ancient times of human medicine. They bind to specific protein-based targets and have influence on their biochemical/physiological functions. Therefore, discovery of new therapeutics and their biomolecular targets have been important in the past decades (Duan et al., 2014). Flavonoids have been one of the important groups of plant-based compounds which show significant activity in several defects and diseases (Aksoy-Sagirli et al., 2015; Hettihewa et al., 2018). A significant number of studies on potential anticancer activity of flavonoidshas been carried out (Chahar et al., 2011; Batra \& Sharma, 2013; Martinez-Perez et al., 2014; López-Lázaro, 2002). Considering these two valuable factors, i.e., TrxR and flavonoids, we decided to investigate the biological activity of flavonoids on TrxR.

In this study, some common flavonoids, which are known to have several biological activities and a represent in poultry feedstuffs were determined. The aim of this study is to investigate the inhibitory effects of some common flavonoids on the enzyme thioredoxin reductase purified from chicken liver.

\section{MATERIAL AND METHODS}

\section{Chemicals}

Sodium dodecyl sulfate (SDS), sodium chloride, sodium acetate, hydrochloric acid, phosphoric acid, ethanol, methanol, isopropanol, acetic acid, sodium acetate, potassium chloride, ethylenediamine tetraacetic acid (EDTA), and $\beta$-mercaptoethanol were purchased from Merck (Darmstadt, Germany); hesperidin, naringenin, chlorogenic acid, ferulic acid, naringin, 3,4-dihydoxybenzoic acid, and ellagic acid were obtained from Sigma (Munich, Germany)and other chemicals required for the investigation steps were acquired from Sigma-Aldrich (St. Louis, MO, USA) and used without any additional purification. Deionized water from the UV version of Millipore, Direct-Q 3, was used for the preparation of the solutions in the investigations.

\section{Natural source}

Chick liver was selected as natural source for thioredoxin reductase. The livers were purchased from a poultry farm in Ağrı, Turkey, and brought to the laboratory in accordance with the cold chain procedures.

\section{Homogenate preparation and heat denaturation}

A buffer solution of $10 \mathrm{mM}$ Tris/ $\mathrm{HCl}(\mathrm{pH} 7.5)$ with 1 $\mathrm{mM}$ ethylenediamine tetraacetic acid (EDTA) was used to wash the liver tissues, and the same buffer was used to prepare liver lysate with the aid of a homogenizer. The lysate was then centrifuged at the rate of 12,700 rpm for $30 \mathrm{~min}$. After this process, the precipitate was firstly discarded and then the supernatant was removed. This supernatant was stored at $60^{\circ} \mathrm{C}$ for 9-10 min and then centrifuged for the second time at the rate of $12,700 \mathrm{rpm}$ for $30 \mathrm{~min}$ to remove the precipitate and the supernatant. Filter paper was utilized to filtrate the supernatant, which was then applied to the affinity column.

\section{Purification with affinity chromatography}

A column with $10 \mathrm{~mL}$ bed volume was designed with $3 \mathrm{~g}$ dried 2', 5'-ADP Sepharose 4B. Distilled water $(300 \mathrm{~mL}$ ) was flushed through the gel system to remove any undesired particles and air. The system was then suspended in $10 \mathrm{mM}$ Tris/HCl buffer with $1 \mathrm{mM}$ EDTA (pH 7.5) and packed into the column. After the gel precipitation step, the chromatographic column system was equilibrated with the same buffer using a peristatic pump at the flow rate of $30 \mathrm{~mL} / \mathrm{h}$ for the washing and equilibration steps. For the purification of target enzyme (TrxR), the biosolution was injected into the $2^{\prime}, 5^{\prime}$-ADP Sepharose 4B column system and the affinity column was washed with the equilibration buffer and $0.15 \mathrm{M} \mathrm{K}$-phosphate buffer with $2 \mathrm{mM}$ EDTA ( $\mathrm{pH}$ 7.5) until final absorbance difference fixed at 0.05 at $280 \mathrm{~nm}$. NADP+ equilibration buffer with a 0 to $10 \mathrm{mM}$ gradient was used to elute TrxR and the active biomolecules were obtained and dialyzed with equilibration buffer.

\section{Sodium dodecyl sulfate polyacrylamide gel electrophoresis (SDS-PAGE)}

SDS-PAGE was performed after the TrxRpurification step. TrxR purity grade and monomer molecular 
mass were obtained in SDS-PAGE with 3\% and 10\% acrylamide for stacking and running gel, respectively, with 0.1 SDS according to the procedure of Laemmli (Laemmli, 1970).

\section{Protein determination}

Protein content during homogenate preparation and purification steps was spectrophotometrically determined at $595 \mathrm{~nm}$, according to the Bradford method with the use of bovine serum albumin as standard (Bradford, 1976).

\section{Enzyme activity determination}

TrxR activity was spectrophotometrically assayed at $412 \mathrm{~nm}$ absorbance using a Shimadzu spectrophotometer (UV-1800). The assay is based on the NADPH-dependent reduction of the substrate, reacting with 5,5 -dithio-bis(2-nitrobenzoic acid) (DTNB). The enzymatic reaction was carried out in a total volume of $1 \mathrm{~mL}, 200 \mu \mathrm{M}$ NADPH, $2 \mathrm{mM}$ DTNB and $1 \mathrm{mM}$ EDTA in $300 \mathrm{mM} \mathrm{K}$-phosphate buffer $(\mathrm{pH}$ 7.75). A value of $13.6 \mathrm{mM}^{-1} \mathrm{~cm}^{-1}$ for the extinction coefficient of DTNB was applied for the calculations.

\section{Kinetic studies and in-vitro inhibition assay}

To obtain the DTNB $K_{M}$ values of the TrxR enzyme, enzymatic measurements were assayed using five different DTNB concentrations. Lineweaver-Burk graphs were drawn from the obtained data and the $K_{M}$ value was calculated from these graphs (Lineweaver \& Burk, 1934). To determine the effects of flavonoids on the TrxR enzyme, enzyme activity was measured using saturated substrate concentration and five different flavonoid concentrations as follows: hesperidin (0.0066-0.33 mM), naringenin (0.011-0.11 $\mathrm{mM})$, chlorogenic acid (0.00564-0.282 mM), ferulic acid (0.155-1.55 mM), naringin (0.052-0.78 mM), 3,4-dihydoxybenzoic acid (0.13-1.3 mM) and ellagic acid (0.001-0.02 mM). The flavonoid concentrations that caused $50 \%$ inhibition (IC50) were obtained via the graphs of \% activity-flavonoid concentration. Cheng-Prusoff equation was used to calculate Ki constants (Yung-Chi \& Prusoff, 1973).

\section{RESULTS AND DISCUSSION}

\section{Purification of TrxR from natural source}

After lysis and clarification, purification procedure was carried out. TrxR purification was performed in two steps with the use of heat denaturation and chromatography step including affinity matrix of $2^{\prime}, 5^{\prime}$ ADP Sepharose $4 B$. The affinity matrix is used to purify the enzymes which use NADP ${ }^{+}$and NADPH coenzymes because of their strong affinity features against these kinds of enzymes (Adem \& Ciftci, 2012). As a result of the purification step, TrxR from chick liver was purified 94.6-fold with a yield of $4.86 \%$ and a specific activity of $0.19 \mathrm{EU} / \mathrm{mg}$, as shown in Table 1.

Table 1 - Affinity purification procedure for TrxR from chick liver.

\begin{tabular}{|c|c|c|c|c|c|c|c|}
\hline Fractions & Activity $(\mathrm{EU} / \mathrm{mL})$ & Volume $(\mathrm{mL})$ & Protein $(\mathrm{mg} / \mathrm{mL})$ & Total activity (EU) & $\begin{array}{l}\text { Specific activity } \\
\text { (EU/mg protein) }\end{array}$ & Recovery $100 \%$ & $\begin{array}{l}\text { Purification } \\
\text { fold }\end{array}$ \\
\hline Homogenate & 0.081 & 24 & 39.76 & 1.944 & 0.0020 & 100 & 1 \\
\hline Heat denaturation & 0.074 & 19 & 18 & 1.406 & 0.0041 & 72.33 & 2.0 \\
\hline $2^{\prime}, 5^{\prime}$-ADP Sepharose 4B & 0.021 & 4.5 & 0.109 & 0.0945 & 0.1927 & 4.86 & 94.6 \\
\hline
\end{tabular}

Lineweaver-Burk plots were drawn by measuring five different DTNB concentrations for the calculation of $K_{M}$ and $V$ max values. $K_{M}$ and $V_{\max }$ values of TrxR for DTNB were calculated as $0.9 \mathrm{mM}$ and $0.03 \mathrm{EU} / \mathrm{mL}$, respectively.

\section{SDS-PAGE analysis}

To verify the purified enzyme from affinity chromatographic column was obtained with SDS-PAGE analysis and one single band was plotted from the gel (Figure 1). As shown in Figure 1, the bands obtained with the purification procedure were clear, consistent, showing good integrity and no diffusion. The mobility of units and/or subunits in SDS-PAGE indicates their molecular weight (MW) (Wang et al., 2016), andMWsof SDS-PAGE bands are calculated according to standard biomarkers (Guo et al., 2017). The MW of the purified enzyme was calculated as $\sim 54 \mathrm{kDa}$ with the use of Rf-log MW as standard biomarkers. $\beta$-galactosidase $(116 \mathrm{kDa})$, lactorferrin $(90 \mathrm{kDa})$, pyruvate kinase $(58 \mathrm{kDa})$, fumarase (48.5 kDa), lactate dehydrogenase (36.5 kDa) were used as standards in Line 1.

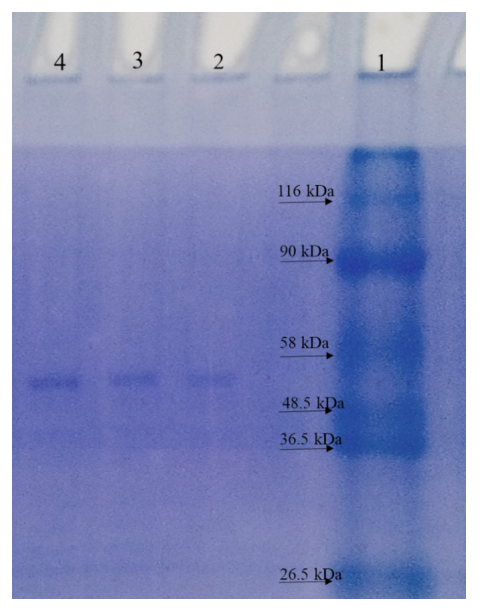

Figure 1 - SDS-PAGE image of the enzyme purified from chick liver. 
Other studies indicate that TrxR from rat liver has a molecular weight of $58 \mathrm{kDa}$ (Luthman \& Holmgren, 1982), $56 \mathrm{kDa}$ as mitochondrial enzyme from bovine adrenal cortex (Watabe et al., 1999), 55.2 kDa from human placenta (Gromer et al., 1998), 70 kDa from trout liver and 64.1 kDa from trout gill tissues (Akyol \& Kuzu, 2017).

\section{Effects of flavonoids on the enzymatic activity}

Understanding the physiological and biochemical mechanism of the cellular biotargets is a vital mission for scientists (Zhang et al., 2016). Numerous antitumor drugs/ligands exert their biological effects through biometabolic pathways of enzyme inhibition. Therefore, enzyme inhibition studies have become increasing important in pharmaceutical research. TrxR is one of the biomolecular targets containing a selenocysteine on the flexible C-terminal arm, which is easily accessible to ligands during catalysis. Numerous electrophilic ligands may irreversibly and selectively interact with this active amino acid site (Urig \& Becker, 2006). In this context, we hypothesized that TrxR inhibition may be an essential point causing the inhibition of tumor growth by blocking redox-dependent biological effects of thioredoxin.

In recent years, many research groups have worked on ligands that affect enzyme activity. It was demonstrated that some compounds are able to inhibit TrxR enzymatic reaction rate by $50 \%$ or more (Cortés et al., 2001; Deponte et al., 2005). Here we would like to give a brief overview of natural TrxR inhibitors in the literature.

Though this study has emphasized the significance of TrxR inhibition from the perspective of its antitumor activity, TrxR plays a major physiological role in several defects and diseases, such as AIDS, rheumatoid arthritis, reperfusion injury, etc. Therefore, TrxR inhibitors have several pharmaceutical applications in these defects and diseases as well as cancer. The inhibitory effect of some heavy metal ions, including $\mathrm{Ni}^{2+}, \mathrm{Cu}^{2+}, \mathrm{Pb}^{2+}, \mathrm{Cr}^{3+}$, $\mathrm{Fe}^{3+}$, and $\mathrm{Ag}^{+}$, on TrxR purified from rainbow troutgill tissues (Akyol \& Kuzu, 2017) was evaluated, and $\mathrm{Ag}^{+}$ showed the strongest inhibitory effect on mitochondrial TrxR. The active site of TrxR contains the amino acid cysteine (Cys), and it is reported that the active sites and/or catalytic regions of enzymes containing Cys are inhibited by metal ions such as $\mathrm{Hg}^{2+}$ and $\mathrm{Ag}^{+}$(Akyol \& Kuzu, 2017). Curcumin is a major polyphenol molecule derived from Curcuma longa. The biomolecule has been therapeutically used in traditional medicine over the centuries, and has shown several therapeutic effects on cellular mechanisms of different diseases such as cancer (Teiten et al., 2010). Fang et al. (2005) showed that curcumin, which is used daily by millions of people, inhibits TrxR activity in rats at a IC ${ }_{50}$ value of 3.6 $\mathrm{mM}$ after incubation at $25^{\circ} \mathrm{C}$ for $2 \mathrm{~h}$ in vitro. Quinones are natural compounds used in several applications in life and medical sciences. They act as electron carriers in photosynthesis and they are used to treat some diseases and defects due to their antioxidant and therapeutic characteristics (El-Najjar et al., 2011). Xu \& Arnér (2012) have demonstrated the inhibitory effects of pyrroloquinoline quinones (PQQs) on TrxR. PQQs are active redox cofactors of bacterial quinoproteins and, in micromolar concentrations, effectively inhibit the activity of TrxR. Isothiocyanates occur in a wide range of vegetables and have numerous biological and pharmacological properties. These natural compounds are powerful inhibitors for carcinogenesis (London et al., 2000). According to Jakubíková and colleagues (2006), isothiocyanates inhibit the activity of cellular TrxRbyTrx accumulation. Flavonoids are compounds derived from vegetables and fruits, and it is claimed they have several health promoting actions due their biochemical and pharmacological characteristics (Lautraite et al., 2002). Several research groups have investigated the potential of flavonoids to inhibit carcinogenesis (Liu et al., 2008; Zhang et al., 2004). Lu et al. (2006) examined the bioactivities of some flavonoids on $\operatorname{Tr} x R$ and found that myricetin $\left(\mathrm{IC}_{50}\right.$ value of $0.62 \mathrm{mM})$ and quercetin $\left(\mathrm{IC}_{50}\right.$ value of $\left.0.97 \mathrm{mM}\right)$ have strong inhibitory characteristics on mammalian TrxR. Powis et al. (2006) evaluated the inhibitory activity analogs of a fungal metabolite, palmarumycin, on human TrxR and MCF-7 breast cancer cells, and reported that PX-960 showed the strongest inhibitory effect $\left(\mathrm{IC}_{50}: 0.27 \mu \mathrm{M}\right)$ against human TrXR, where as palmarumycin CP1 was the most effective against MCF-7 breast cancer cells, with an $I C_{50}$ value of 1.0 $\mu \mathrm{M}$.

To the best of our knowledge, there are no experimental data on the bioactivities of flavonoids on chick liver TrxR. In the present study, chicken liver TrxR was treated with various concentrations of commercial flavonoids, including hesperidin, naringenin, chlorogenic acid, ferulic acid, naringin, 3,4-dihydoxybenzoic acid, and ellagic acid, to evaluate their bioactivity against TrxR. As illustrated in Figure 2, chicken liver TrxR activity was inhibited by the evaluated flavonoids in a dose-dependent manner. Ellagic acid showed the strongest inhibitory effect on TrxR, followed by naringenin and chlorogenic acid. 

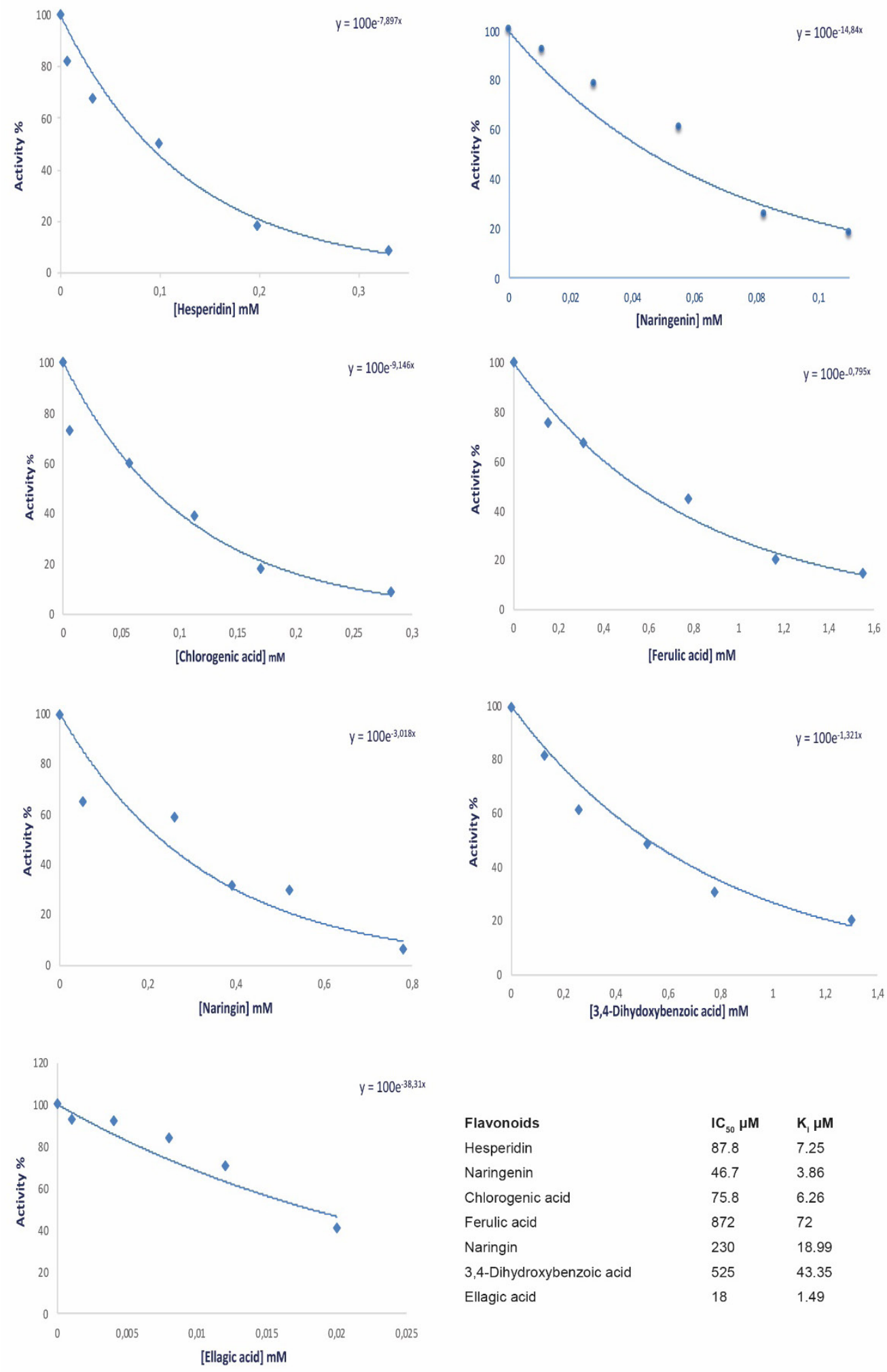

$\begin{array}{lll}\text { Flavonoids } & \mathbf{I C}_{50} \mathbf{\mu M} & \mathbf{K}_{\mathbf{1}} \boldsymbol{\mu M} \\ \text { Hesperidin } & 87.8 & 7.25 \\ \text { Naringenin } & 46.7 & 3.86 \\ \text { Chlorogenic acid } & 75.8 & 6.26 \\ \text { Ferulic acid } & 872 & 72 \\ \text { Naringin } & 230 & 18.99 \\ \text { 3,4-Dihydroxybenzoic acid } & 525 & 43.35 \\ \text { Ellagic acid } & 18 & 1.49\end{array}$

\section{CONCLUSIONS}

The cytosolic TrxR enzyme was first purified from chicken livers by electrophoretic homogenization, and the molecular weight of the enzyme was calculated.
Briefly, we have demonstrated that flavonoids, as natural products, are potent inhibitors of thioredoxin reductase activity. This finding indicates that the content of flavonoids in animal diets may alter metabolic pathways by influencing TrxR activity. In addition, the 
synthesis of flavonoids and their derivatives is pharmacologically important in further studies targeting the inhibition ofTrxR activity.

\section{AUTHOR CONTRIBUTIONS}

The authors conceived, designed the experiments and contributed equally to this study.

\section{CONFLICTS OF INTEREST}

The authors declare no conflict of interest.

\section{REFERENCES}

Adem S, Ciftci M. Purification of rat kidney glucose 6-phosphate dehydrogenase, 6-phosphogluconate dehydrogenase, and glutathione reductase enzymes using $2^{\prime}, 5^{\prime}$-ADP Sepharose $4 B$ affinity in a single chromatography step. Protein Expression and Purification 2012;81:1-4.

Aksoy-Sagirli P, Ozsoy N, Ecevit-Genc G, Melikoglu G. In vitro antioxidant activity, cyclooxygenase-2, thioredoxin reductase inhibition and DNA protection properties of Teucrium sandrasicum L. Industrial Crops and Products 2015;74:545-550.

Akyol H, Kuzu M. In vitro effects of some heavy metal ions on cytosolic thioredoxin reductase purified from rainbow trout gill tissues. Fresenius Environmental Bulletin 2017;26:4677-4683.

Arnér ESJ, Holmgren A. Physiological functions of thioredoxin and thioredoxin reductase. European Journal of Biochemistry 2000;267:6102-6109.

Arnér ESJ. Focus on mammalian thioredoxin reductases - Important selenoproteins with versatile functions. Biochimica et Biophysica Acta 2009; 1790:495-526

Batra P, Sharma AK. Anti-cancer potential of flavonoids: recent trends and future perspectives. 3 Biotechnology 2013;3:439-459.

Becker K, Gromer S, Schirmer RH, Müller S. Thioredoxin reductase as a pathophysiological factor and drug target. European Journal of Biochemistry 2000;267:6118-6125.

Bindoli A, Rigobello MP, Scutari G, Gabbiani C, Casini A, Messori L. Thioredoxin reductase: A target for gold compounds acting as potential anticancer drugs. Coordination Chemistry Reviews 2009;253:16921707.

Bradford MM. A rapid and sensitive method for the quantitation of microgram quantities of protein utilizing the principle of protein-dye binding. Analytical Biochemistry 1976;72:248-254.

Cai W, Zhang L, Song Y, Wang B, Zhang B, Cui X, Hu G, Liu Y, Wu J, Fang J. Small molecule inhibitors of mammalian thioredoxin reductase. Free Radical Biology and Medicine 2012;52:257-265.

Chahar MK, Sharma N, Dobhal MP, Joshi YC. Flavonoids: A versatile source of anticancer drugs. Pharmacognosy Reviews 2011;5:1-12.

Choi JH, Kim TN, Kim S, Baek SH, Kim JH, Lee SR, Kim JR. Overexpression of mitochondrial thioredoxin reductase and peroxiredoxin III in hepatocellular carcinomas. Anticancer Research 2002;22:3331-3335.

Cortés A, Cascante M, Cárdenas ML, Cornish-Bowden A. Relationships between inhibition constants, inhibitor concentrations for 50\% inhibition and types of inhibition: new ways of analysing data. Biochemical Journal 2001;357:263-268.
Deponte M, Urig S, Arscott LD, Fritz-Wolf K, Réau R, Herold-Mende C, et al. Mechanistic studies on a novel, highly potent gold-phosphole inhibitor of human glutathione reductase. The Journal of Biological Chemistry 2005;280:20628-20637.

Duan D, Zhang B, Yao J, Liu Y, Sun J, Ge C, et al. Gambogic acid induces apoptosis in hepatocellular carcinoma SMMC-7721 cells by targeting cytosolic thioredoxin reductase. Free Radical Biology and Medicine 2014;69:15-25.

El-Najjar N, Gali-Muhtasib H, Ketola RA, Vuorela P, Urtti A, Vuorela H. The chemical and biological activities of quinones: Overview and implications in analytical detection. Phytochemistry Reviews 2011;10:353-370.

Fang J, Lu J, Holmgren A. Thioredoxin reductase is irreversibly modified by curcumin: A novel molecular mechanism for its anticancer activity. The Journal of Biological Chemistry 2005;280:25284-25290.

Gromer S, Arscott LD, Williams CH, Schirmeri RH, Becker K. Human placenta thioredoxin reductase. Isolation of the selenoenzyme, steady state kinetics, and inhibition by therapeutic gold compounds. The Journal of Biological Chemistry 1998;273:20096-20101.

Guo L, Wu Y, Liu M, Wang B, Ge Y, Chen Y. Determination of edible bird's nests by FTIR and SDS-PAGE coupled with multivariate analysis. Food Control 2017;80:259-266.

Hettihewa SK, Hemar Y, Rupasinghe HPV. Flavonoid-rich extract of actinidia macrosperma (A Wild Kiwifruit) Inhibits Angiotensin-Converting Enzyme In Vitro. Foods 2018;7:146.

Hirt RP, Müller S, Embley TM, Coombs GH. The diversity and evolution of thioredoxin reductase: new perspectives. Trends in Parasitology 2002:18:302-308

Holmgren A, Lu J. Thioredoxin and thioredoxin reductase: Current research with special reference to human disease. Biochemical and Biophysical Research Communications 2010;396:120-124.

Jakubíková J, Sedlák J, Bod'o J, Bao Y. Effect of isothiocyanates on nuclear accumulation of NF-kB, Nrf2, and thioredoxin in Caco-2 cells. Journal of Agricultural and Food Chemistry 2006;54:1656-1662.

Laemmli UK. Cleavage of structural proteins during the assembly of the head of bacteriophage T4. Nature 1970;227:680-685

Lautraite S, Musonda AC, Doehmer J, Edwards GO, Chipman JK. Flavonoids inhibit genetic toxicity produced by carcinogens in cells expressing CYP1A2 and CYP1A1. Mutagenesis 2002;17:45-53.

Lineweaver $\mathrm{H}$, Burk $\mathrm{D}$. The determination of enzyme dissociation constants Journal of the American Chemical Society1934;56:658-666.

Liu F-T, Agrawal SG, Movasaghi Z, Wyatt PB, Rehman IU, Gribben JG, et al. Dietary flavonoids inhibit the anticancer effects of the proteasome inhibitor bortezomib. Blood 2008:112:3835-3846.

London SJ, Yuan JM, Chung FL, Gao YT, Coetzee GA, Ross RK, Yu MC. Isothiocyanates, glutathione S-transferase M1 and T1 polymorphisms, and lung-cancer risk: a prospective study of men in Shanghai, China. Lancet 2000;356:724-729.

López-Lázaro M. Flavonoids as anticancer agents: structure-activity relationship study. Current Medicinal Chemistry - Anti-Cancer Agents 2002:2:691-714.

Lu J, Papp LV, Fang J, Rodriguez-Nieto S, Zhivotovsky B, Holmgren A Inhibition of mammalian thioredoxin reductase by some flavonoids: implications for myricetin and quercetin anticancer activity. Cancer Research 2006;66:4410-4418.

Luthman M, Holmgren, A. Rat liver thioredoxin and thioredoxin reductase: purification and characterization. Biochemistry 1982;21:6628-6633. 
Martinez-Perez C, Ward C, Cook G, Mullen P, McPhail D, Harrison DJ, Langdon SP. Novel flavonoids as anti-cancer agents: mechanisms of action and promise for their potential application in breast cancer. Biochemical Society Transactions 2014;42:1017-1023.

Montano SJ, Lu J, Gustafsson TN, Holmgren A. Activity assays of mammalian thioredoxin and thioredoxin reductase: Fluorescent disulfide substrates, mechanisms, and use with tissue samples. Analytical Biochemistry 2014;449:139-146.

Pacitti D, Wang T, Martin SAM, Sweetman J, Secombes CJ. Insights into the fish thioredoxin system: Expression profile of thioredoxin and thioredoxin reductase in rainbow trout (Oncorhynchus mykiss) during infection and in vitro stimulation. Developmental and Comparative Immunology 2014;42:261-277.

Powis G, Wipf P, Lynch SM, Birmingham A, Kirkpatrick DL. Molecular pharmacology and antitumor activity of palmarumycin-based inhibitors of thioredoxin reductase. Molecular Cancer Therapeutics 2006;5:630636.

Soini $Y$, Kahlos K, Näpänkangas $U$, Kaarteenaho-Wiik R, Säily $M$, et al. Widespread expression of thioredoxin and thioredoxin reductase in non-small cell lung carcinoma. Clinical Cancer Research 2001;7:17501757.

Teiten MH, Eifes S, Dicato M, Diederich M. Curcumin-the paradigm of a multi-target natural compound with applications in cancer prevention and treatment. Toxins 2010;2:128-162.

Temel Y, Kufrevioglu Öi, Ciftci M. Investigation of the effects of purification and characterization of turkey (Meleagris gallopavo) liver mitochondrial thioredoxin reductase enzyme and some metal ions on enzyme activity. Turkish Journal of Chemistry 2017;41:48-60.

Urig S, Becker K. On the potential of thioredoxin reductase inhibitors for cancer therapy. Seminars in Cancer Biology 2006;16:452-465.
Wang $\mathrm{X}$, Zhang J, Xu T. Thioredoxin reductase inactivation as a pivotal mechanism of ifosfamide in cancer therapy. The European Journal of Pharmacology 2008;579:66-73.

Wang Y, Zheng QY, Guo ZR, Qiao YY, Cao YL, Liu CH, et al.. A missense mutation affects the mobility of high molecular weight glutenin Dy10 subunit in SDS-PAGE. Agri Gene 2016;2:1-4.

Watabe S, Makino Y, Ogawa K, Hiroi T, Yamamoto Y, Takahashi SY. Mitochondrial thioredoxin reductase in bovine adrenal cortex: Its purification, properties, nucleotide/amino acid sequences, and identification of selenocysteine. European Journal of Biochemistry 1999;264:74-84.

Xu J, Arnér ESJ. Pyrroloquinoline quinone modulates the kinetic parameters of the mammalian selenoprotein thioredoxin reductase 1 and is an inhibitor of glutathione reductase. Biochemical Pharmacology 2012;83:815-820

Yung-Chi C, Prusoff WH. Relationship between the inhibition constant (KI) and the concentration of inhibitor which causes 50 per cent inhibition (150) of an enzymatic reaction. Biochemical Pharmacology 1973;22:3099-3108.

Zhang J, Li Y, Duan D, Yao J, Gao K, Fang J. Inhibition of thioredoxin reductase by alantolactone prompts oxidative stress-mediated apoptosis of HeLa cells. Biochemical Pharmacology 2016;102:34-44.

Zhang $S$, Yang $X$, Morris ME. Flavonoids are inhibitors of breast cancer resistance protein (ABCG2)-mediated transport. Molecular Pharmacology 2004;65:1208-1216.

Zhou B, Huang J, Zuo Y, Li B, Guo Q, Cui B, et al. 2a, a novel curcumin analog, sensitizes cisplatin-resistant A549 cells to cisplatin by inhibiting thioredoxin reductase concomitant oxidative stress damage. The European Journal of Pharmacology 2013;707:130-139. 
